\title{
Diagnostic qPCR Assay to Detect Fusarium brasiliense, a Causal Agent of Soybean Sudden Death Syndrome and Root Rot of Dry Bean
}

\author{
Mitchell G. Roth, ${ }^{1,2}$ Kjersten A. Oudman, ${ }^{1}$ Amanda Griffin, ${ }^{1}$ Janette L. Jacobs, ${ }^{1}$ Hyunkyu Sang, ${ }^{1}$ and Martin I. Chilvers ${ }^{1,2, \dagger}$ \\ ${ }^{1}$ Department of Plant, Soil and Microbial Sciences Michigan State University, East Lansing, MI 48824 \\ ${ }^{2}$ Genetics Graduate Program, Michigan State University, East Lansing, MI 48824
}

\begin{abstract}
Species within clade 2 of the Fusarium solani species complex (FSSC) are significant pathogens of dry bean (Phaseolus vulgaris) and soybean (Glycine max), causing root rot and/or sudden death syndrome (SDS). These species are morphologically difficult to distinguish and often require molecular tools for proper diagnosis to a species level. Here, a TaqMan probe-based quantitative PCR (qPCR) assay was developed to distinguish Fusarium brasiliense from other closely related species within clade 2 of the FSSC. The assay displays high specificity against close relatives and high sensitivity, with a detection limit of $100 \mathrm{fg}$. This assay was able to detect $F$. brasiliense from purified mycelia, infected

accurate quantification of both $F$. brasiliense and $F$. virguliforme was obtained, which can facilitate accurate diagnoses and identify coinfections with a single reaction. The assay is compatible with multiple qPCR thermal cycling platforms and will be helpful in providing accurate detection of $F$. brasiliense. Management of root rot and SDS pathogens in clade 2 of the FSSC is challenging and must be done proactively, because no midseason management strategies currently exist. However, accurate detection can facilitate management decisions for subsequent growing seasons to successfully manage these pathogens.
\end{abstract} dry bean roots, and soil samples throughout Michigan. When multiplexed with an existing qPCR assay specific to Fusarium virguliforme,
Keywords: field crops, fungi, oilseeds and legumes, pathogen detection
The Fusarium solani species complex (FSSC) is composed of three major clades designated 1, 2, and 3 (Chitrampalam and Nelson 2016; O'Donnell 2000). Some Fusarium species within clade 2 are soilborne plant pathogens that cause root rot of soybean (Glycine max) and dry bean (Phaseolus vulgaris) (Aoki et al. 2014; Chitrampalam and Nelson 2016). Macroscopic and microscopic morphological features of the species within clade 2 are very challenging to differentiate, because all produce similar pigments, and conidia lengths and widths overlap (Aoki et al. 2003). Of the species within this clade, six are known to cause sudden death syndrome (SDS) on soybean (Aoki et al. 2003, 2005, 2012a, b; Tewoldemedhin et al. 2017). In South America, the SDS-causing pathogens include Fusarium virguliforme $\mathrm{O}$ 'Donnell \& $\mathrm{T}$ Aoki, Fusarium brasiliense $\mathrm{T}$ Aoki \& O'Donnell, Fusarium tucumaniae, and Fusarium crassistipitatum, whereas in North America, SDS is caused by F. virguliforme and F. brasiliense (Wang et al. 2019b). Fusarium brasiliense and an undescribed Fusarium sp. cause soybean SDS in South Africa (Tewoldemedhin et al. 2017). The sixth SDS-causing species, Fusarium azukicola, has only been isolated from adzuki bean (Vigna angularis), but when inoculated on soybeans, it caused foliar SDS symptoms (Aoki et al. 2012b).

Soybean SDS is an annual threat in both the United States and Brazil (Aoki et al. 2003; O’Donnell et al. 2010). These countries dominate soybean production in North and South America, respectively, both producing an estimated 120 million metric tons of soybeans in 2017 to 2018 (USDA 2018). Managing these SDS-causing FSSC

${ }^{\dagger}$ Corresponding author: M. I. Chilvers; chilvers@msu.edu

Funding: This work was funded in part by the Michigan Soybean Promotion Committee, the Michigan Dry Bean Commission, the Michigan Department of Agriculture and Rural Development, Bayer CropSciences, the Syngenta Agricultural Scholarship, and Project GREEEN.

The author(s) declare no conflict of interest.

Accepted for publication 9 July 2019.

This article is in the public domain and not copyrightable. It may be freely reprinted with customary crediting of the source. The American Phytopathological Society, 2020 clade 2 species is challenging, because few fungicides demonstrate efficacy (Kandel et al. 2018; Sang et al. 2018; Wang et al. 2017), genetic resistance is partial (Chang et al. 2018), and crop rotation practices take up to 3 or 4 years of nonhost crops to lower SDS pressure (Leandro et al. 2018). However, some SDS-causing species, like $F$. tucumaniae, show increased sensitivity to certain chemistries (Sang et al. 2018), and therefore, it is important to know the species present to recommend proper management.

Monitoring the spread of fungal pathogens is also important to determine if management strategies are effective. Fungal pathogens can be spread through the transfer of infected materials, shared use of contaminated field equipment, and wind-blown spores. The mechanism of $F$. virguliforme spread remains unknown, although the sexual stage has never been observed, and only one mating type has been detected (Hughes et al. 2014). Therefore, spread through the discharge of sexual ascospores seems unlikely. A single mating type for $F$. brasiliense was identified in South Africa (Tewoldemedhin et al. 2017), but both mating types have been found in South America (Hughes et al. 2014) and Michigan isolates (K. A. Oudman et al., unpublished data). In addition, $F$. brasiliense isolates with different mating types were identified in the same field (K. A. Oudman et al., unpublished data). This indicates that conventional fungal sexual reproduction is probable in $F$. brasiliense, providing an opportunity for the pathogen to produce perithecia and spread through the discharge of sexual ascospores into the air. Only one isolate of $F$. brasiliense had been identified in the United States before 2014 from an unknown host in California (Aoki et al. 2005), and therefore, it is unlikely that it has spread from California to Michigan without being detected in soybean-growing states in between. Population genetic studies of $F$. virguliforme suggest that it originated in South America and spread to North America (Wang 2016). It may be possible that $F$. brasiliense also originated in South America and spread to the United States through unknown mechanisms, but a native Michigan population of $F$. brasiliense cannot be ruled out.

Because both soybeans and dry beans are hosts for Fusarium root rot pathogens, accurate identification of these species in these fields is critical to prevent significant inoculum increases, severe yield losses, and potential spread to neighboring fields. Accurate identification of $F$. brasiliense and monitoring its spread throughout the United States will allow growers to implement the few successful 
management strategies available. Additionally, with consumer trends increasing the demand for non-genetically modified foods, many dry bean growers are beginning to rotate non-genetically modified soybeans with dry beans (B. Glass, personal communication), potentially leading to even more significant inoculum increases. Our primary objective was to develop a highly specific and sensitive quantitative PCR (qPCR) assay to detect $F$. brasiliense. The second objective was to validate the performance of this qPCR assay in detecting $F$. brasiliense from purified mycelia, infected plant roots, and soil. Also, we examined the compatibility of this assay with a $F$. virguliforme $\mathrm{qPCR}$ assay for multiplexing purposes, which provides fast and efficient diagnosis of closely related species or the presence of coinfections.

\section{Materials and Methods}

Assay design. The intergenic spacer (IGS) region of the ribosomal RNA gene has been used to distinguish species within the FSSC (Wang et al. 2011), including SDS- and brown root rot-causing fusaria (O'Donnell et al. 2010), and it was used as the target locus for this assay as in other qPCR assays (Chilvers et al. 2007; Okubara et al. 2013; Wang et al. 2015). IGS sequences from species within clade 2 of the FSSC were obtained from the NCBI: F. azukicola GenBank number JQ670149; F. brasiliense GenBank numbers KF706657 and FJ919512; Fusarium cuneirostrum GenBank numbers FJ919511 and FJ919548; F. crassistipitatum GenBank numbers FJ919521 and FJ919554; Fusarium phaseoli GenBank numbers FJ919498, FJ919510, and FJ919500; F. tucumaniae GenBank numbers FJ919507 and FJ919515; and F. virguliforme GenBank numbers FJ919499 and FJ919557. Sequences were aligned in MEGA7 (Kumar et al. 2016) using the MUSCLE algorithm (Edgar 2004).

A TaqMan probe using locked nucleic acids was designed to capitalize on the presence of two single-nucleotide polymorphisms (SNPs) specific to $F$. brasiliense within eight base pairs (bp) of each other (Fig. 1). Primer and probe sequences are reported in Table 1. Each qPCR reaction was performed with two technical replicates and contained $10 \mu$ l of $2 \times$ TaqMan Universal real-time PCR master

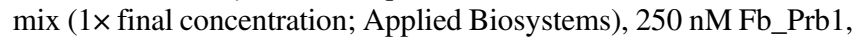
$500 \mathrm{nM}$ Fb_F1 primer, $500 \mathrm{nM}$ Fb_F2 primer, $400 \mathrm{ng}$ of bovine serum albumin (BSA), $2 \mu \mathrm{l}$ of DNA template, and molecular-grade water up to a total reaction volume of $20 \mu \mathrm{l}$. All assays were performed on the StepOnePlus real-time PCR system (v2.3; Applied Biosystems), and they were set up in clear MicroAmp 96-well plates (Thermo-Fisher Scientific), except for multiplexed assays. Multiplexed reactions were performed with two technical replicates, each containing $10 \mu 1$ of $2 \times$ TaqMan Universal real-time PCR master mix

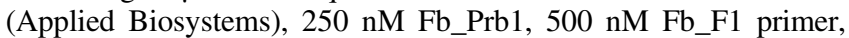
$500 \mathrm{nM}$ Fb_F2 primer, $100 \mathrm{nM}$ FvPrb3, $500 \mathrm{nM}$ F6-3, $500 \mathrm{nM}$ R6, $400 \mathrm{ng}$ of BSA, $2 \mu \mathrm{l}$ of each DNA template, and moleculargrade water up to a total reaction volume of $20 \mu \mathrm{l}$.

qPCR assay specificity. Fusarium isolates used for testing the assay specificity were either collected from counties throughout Michigan or requested from the U.S. Department of Agriculture Agricultural Research Service (ARS) Culture Collection (NRRL) (Table 2). Isolates collected from Michigan were obtained from root tissues of infected soybean or dry bean plants. Briefly, plants displaying stunting or foliar SDS symptoms from fields throughout Michigan were uprooted and transported to the laboratory, where soil was thoroughly washed off roots. Root sections displaying severe discoloration and rot were soaked in $5 \%$ bleach solution $(0.4 \%$ $\mathrm{NaOCl}$ ) for $4 \mathrm{~min}$, rinsed thoroughly in sterile deionized water for $4 \mathrm{~min}$, blotted dry with a sterile paper towel, and plated on WMS agar ( $2 \%$ agar, $15 \mu \mathrm{g} / \mathrm{ml}$ metalaxyl, and $300 \mu \mathrm{g} / \mathrm{ml}$ streptomycin) to select for fungal growth. Plates were incubated for 7 days at room temperature and observed under a dissecting microscope (Leica Microsystems) for the formation of sporodochia. Using an insect pin, macroconidia from a sporodochium were transferred, spread on fresh WMS agar, and allowed to grow for $24 \mathrm{~h}$. Finally, a single germinating macroconidium was aseptically transferred onto full-strength potato dextrose agar (Neogen). Isolates were stored at room temperature on synthetic nutrient agar slants $\left(1 \mathrm{~g} /\right.$ liter $\mathrm{KH}_{2} \mathrm{PO}_{4}, 1 \mathrm{~g} /$ liter $\mathrm{KNO}_{3}$, $0.5 \mathrm{~g} /$ liter $\mathrm{MgSO}_{4}, 0.5 \mathrm{~g} /$ liter $\mathrm{KCl}, 0.2 \mathrm{~g} /$ liter glucose, $0.2 \mathrm{~g} /$ liter sucrose, and $2 \%$ agar) in scintillation vials (Research Products International) for long-term storage.

Macroconidia from pure cultures were inoculated into potato dextrose broth and allowed to grow at room temperature for $48 \mathrm{~h}$ with shaking at $100 \mathrm{rpm}$. DNA was extracted with two similar methods. For testing specificity at a standard $5 \mathrm{ng}$ per reaction, mycelia were

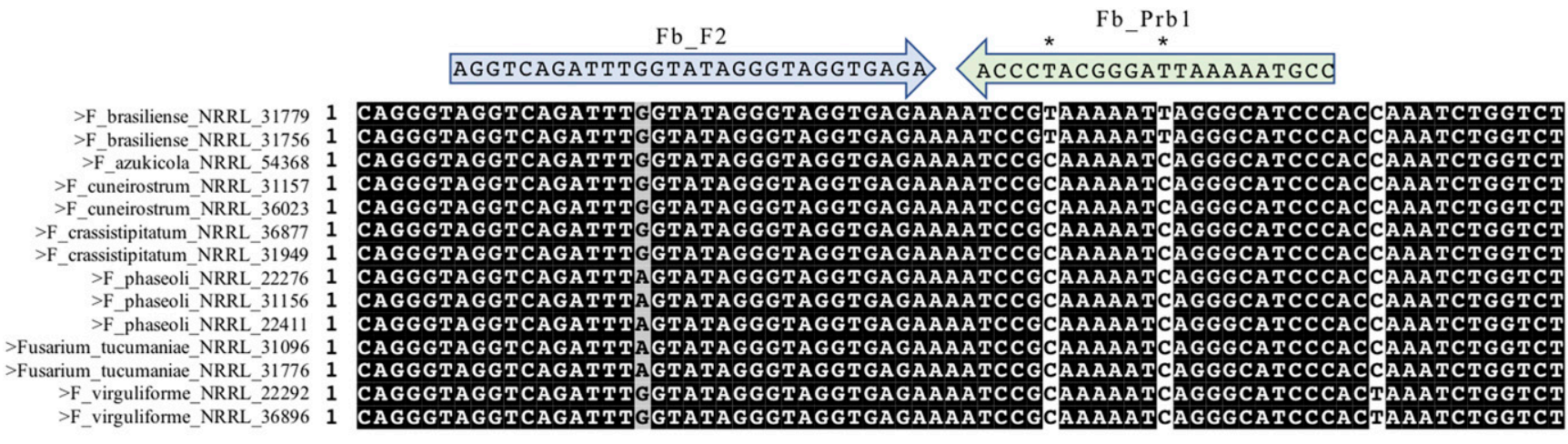

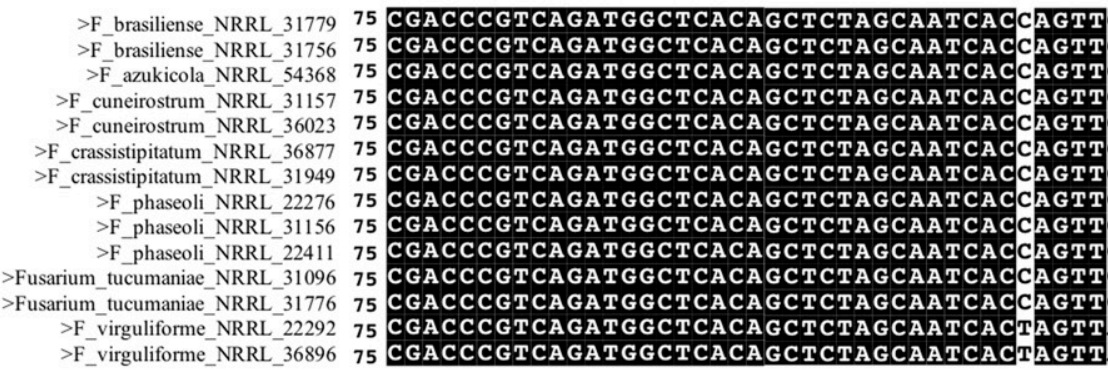

CGACCCGTCAGATGGCTCACAGCTCTAGCAATCA

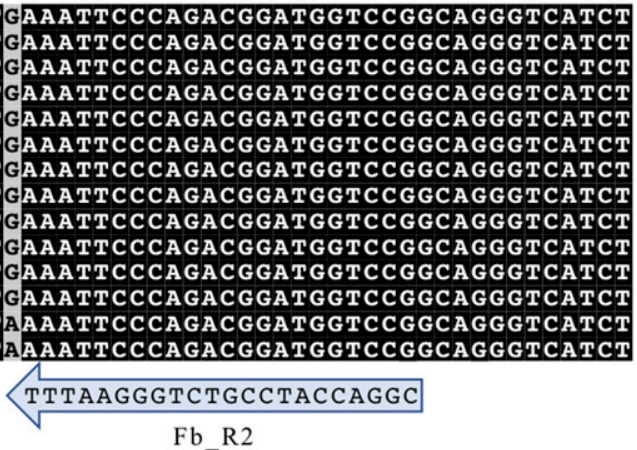

Fig. 1. Sequence alignment of 149 base pairs of the intergenic spacer (IGS) of species within clade 2 of the Fusarium solani species complex. Primers (blue) and probe sequences (green) are displayed as arrows at their annealing location within the IGS. Asterisks represent locked nucleic acids (LNA) designed in the probe. 
filtered from broth with two layers of Miracloth (Millipore Sigma) and rinsed with $200 \mathrm{ml}$ of sterile deionized water. The fresh rinsed mycelia were immediately transferred to a sterile, prechilled mortar and ground with a pestle in the presence of liquid nitrogen. After $\sim 1$ min of tissue disruption, the ground mycelia were immediately transferred into microcentrifuge tubes containing a DNA extraction buffer (200 mM Tris-HCl, $1 \mathrm{M} \mathrm{NaCl}, 25$ mM EDTA, $25 \mathrm{mM}$ sodium dodecyl sulfate, and $100 \mu \mathrm{g}$ of RNaseA) and incubated for $30 \mathrm{~min}$ at room temperature, with gentle inversions every $5 \mathrm{~min}$. Proteinase $\mathrm{K}$ $(200 \mu \mathrm{g})$ was added to each sample, and they were incubated at room temperature for $20 \mathrm{~min}$, with gentle inversions every $5 \mathrm{~min}$. The samples were chilled on ice for $5 \mathrm{~min}$ followed by an addition of $0.2 \mathrm{vol}$ of ice-cold $5 \mathrm{M}$ potassium acetate and another 5-min incubation; then, they were centrifuged at $5,000 \times g$ for $12 \mathrm{~min}$ at $4^{\circ} \mathrm{C}$. The supernatant was transferred to fresh tubes, and an equal volume of 25:24:1 phenol:chloroform:isoamyl alcohol (Millipore Sigma) was added, mixed gently by inversion, and centrifuged. The phenol:chloroform step was repeated followed by an additional step using chloroform only (Millipore Sigma). The DNA was precipitated by adding $0.1 \mathrm{vol}$ of $5 \mathrm{M} \mathrm{NaCl}$ and $1 \mathrm{vol}$ of isopropanol, incubated on ice for

Table 1. Primers and probes used in this study

\begin{tabular}{|c|c|c|c|c|}
\hline Primer/probe name ${ }^{a}$ & Sequence $\left(5^{\prime}\right.$ to $\left.3^{\prime}\right)$ & Length (base pairs) & Temperature $\left({ }^{\circ} \mathbf{C}\right)^{\mathbf{b}}$ & Reference \\
\hline Fb_F2 & AGGTCAGATTTGGTATAGGGTAGGTGAGA & 29 & 67.4 & This study \\
\hline $\mathrm{Fb} \_\mathrm{R} 2$ & CGGACCATCCGTCTGGGAATTT & 22 & 66.3 & This study \\
\hline Fb_Prb1 & 5HEX-TGGGATGCCCT+AATTTTT+ACGG-3IABkFQ & 22 & 64.7 & This study \\
\hline F6-3 & GTAAGTGAGATTTAGTCTAGGGTAGGTGAC & 30 & 57.8 & Wang et al. 2015 \\
\hline R6 & GGGACCACCTACCCTACACCTACT & 24 & 59.6 & Wang et al. 2015 \\
\hline FvPrb-3 & 6FAM-TTTGGTCTAGGGTAGGCCG-MGBNFQ & 19 & 70.0 & Wang et al. 2015 \\
\hline
\end{tabular}

a Probes contain 5' fluorophores "5HEX" or "6FAM" and 3' quenchers "3IABkFQ" or "MGBNFQ."

${ }^{\mathrm{b}}$ Calculated with the OligoAnalyzer tool from IDT using the default quantitative PCR parameter settings.

Table 2. Panel of isolates used to determine specificity of Fusarium brasiliense quantitative PCR assay

\begin{tabular}{|c|c|c|c|c|c|}
\hline Isolate $^{a}$ & Species $^{\mathbf{b}}$ & Host & Location isolated & Assay result ${ }^{\mathbf{c}}$ & $\begin{array}{c}\text { Ct with } 5 \mathrm{ng} \\
\text { of starting } \\
\text { DNA }^{\mathrm{d}}\end{array}$ \\
\hline 54361 & Fusarium azukicola & Vigna angularis & Obihiro, Hokkaido, Japan & - & n.d. \\
\hline 54362 & Fusarium azukicola & Vigna angularis & Obihiro, Hokkaido, Japan & - & n.d. \\
\hline 34938 & Fusarium brasiliense & Unknown & $\begin{array}{l}\text { Vila Maria, Rio Grande } \\
\text { do Sul, Brazil }\end{array}$ & + & 14.92 \\
\hline 22678 & Fusarium brasiliense & Phaseolus vulgaris & California, U.S.A. & + & \\
\hline MI-Mtc-C1 & Fusarium brasiliense & Glycine $\max$ & Montcalm County, MI, U.S.A. & + & 14.21 \\
\hline MI-Mtc-A13 & Fusarium brasiliense & Glycine $\max$ & Montcalm County, MI, U.S.A. & + & 14.43 \\
\hline F-14-12 & Fusarium brasiliense & Phaseolus vulgaris & Ingham County, MI, U.S.A. & + & \\
\hline F-14-42 & Fusarium brasiliense & Phaseolus vulgaris & Montcalm County, MI, U.S.A. & + & 14.71 \\
\hline F-14-44 & Fusarium brasiliense & Phaseolus vulgaris & Montcalm County, MI, U.S.A. & + & \\
\hline F-15-33 & Fusarium brasiliense & Phaseolus vulgaris & Montcalm County, MI, U.S.A. & + & \\
\hline F-15-101 & Fusarium brasiliense & Phaseolus vulgaris & Huron County, MI, U.S.A. & + & \\
\hline F-15-102 & Fusarium brasiliense & Phaseolus vulgaris & Huron County, MI, U.S.A. & + & \\
\hline F-15-144 & Fusarium brasiliense & Phaseolus vulgaris & Montcalm County, MI, U.S.A. & + & \\
\hline F-15-158 & Fusarium brasiliense & Phaseolus vulgaris & Saginaw County, MI, U.S.A. & + & 14.47 \\
\hline F-15-162 & Fusarium brasiliense & Phaseolus vulgaris & Saginaw County, MI, U.S.A. & + & \\
\hline F-15-174 & Fusarium brasiliense & Phaseolus vulgaris & Gratiot County, MI, U.S.A. & + & \\
\hline F-15-192 & Fusarium brasiliense & Phaseolus vulgaris & Michigan, U.S.A. & + & \\
\hline F-16-21 & Fusarium brasiliense & Glycine $\max$ & Montcalm County, MI, U.S.A. & + & \\
\hline F-16-59 & Fusarium brasiliense & Glycine $\max$ & Montcalm County, MI, U.S.A. & + & 13.94 \\
\hline F-16-118 & Fusarium brasiliense & Phaseolus vulgaris & Saginaw County, MI, U.S.A. & + & \\
\hline F-16-119 & Fusarium brasiliense & Phaseolus vulgaris & Saginaw County, MI, U.S.A. & + & \\
\hline F-16-124 & Fusarium brasiliense & Phaseolus vulgaris & Saginaw County, MI, U.S.A. & + & \\
\hline F-16-125 & Fusarium brasiliense & Phaseolus vulgaris & Saginaw County, MI, U.S.A. & + & \\
\hline F-16-127 & Fusarium brasiliense & Phaseolus vulgaris & Saginaw County, MI, U.S.A. & + & \\
\hline F-16-128 & Fusarium brasiliense & Phaseolus vulgaris & Saginaw County, MI, U.S.A. & + & \\
\hline F-16-131 & Fusarium brasiliense & Phaseolus vulgaris & Saginaw County, MI, U.S.A. & + & \\
\hline F-16-136 & Fusarium brasiliense & Phaseolus vulgaris & Saginaw County, MI, U.S.A. & + & \\
\hline F-16-137 & Fusarium brasiliense & Phaseolus vulgaris & Saginaw County, MI, U.S.A. & + & 14.52 \\
\hline 31949 & Fusarium crassistipitatum & Glycine $\max$ & Cristalina, Goias, Brazil & - & n.d. \\
\hline 46170 & Fusarium crassistipitatum & Glycine $\max$ & Las Lajitas, Salta, Argentina & - & \\
\hline 46175 & Fusarium crassistipitatum & Glycine $\max$ & Las Lajitas, Salta, Argentina & - & \\
\hline F-14-52 & Fusarium cuneirostrum & Phaseolus vulgaris & Montcalm County, MI, U.S.A. & - & n.d. \\
\hline Fsp3 & Fusarium cuneirostrum & Phaseolus vulgaris & Uganda, Africa & - & \\
\hline
\end{tabular}

${ }^{a}$ Isolate identifications with only numbers were obtained from the U.S. Department of Agriculture Agricultural Research Service (ARS) Culture Collection (NRRL). All other isolates were obtained by J. L. Jacobs and M. I. Chilvers.

b Fusarium solani species complex 5 (FSSC 5) is named Fusarium solani, whereas FSSC 11 is an unnamed species within clade 3.

$\mathrm{c}+$ indicates positive amplification, whereas - indicates no amplification.

${ }^{\mathrm{d}} \mathrm{Ct}$, cycle threshold; n.d., not determined. 
10 min, and pelleted at $10,000 \times g$ in a refrigerated centrifuge at $4^{\circ} \mathrm{C}$. The pelleted DNA was washed twice with freshly prepared $80 \%$ ethanol and resuspended in $10 \mathrm{mM}$ Tris buffer ( $\mathrm{pH}$ 8.0) overnight. DNA quality was determined via 260/280- and 260/230-nm readings obtained from a Nanodrop 1000 (Thermo-Fisher Scientific), and quantity was determined via the Qubit dsDNA BR Assay Kit (Thermo-Fisher Scientific). An aliquot of DNA for each strain was diluted to $2.5 \mathrm{ng} / \mu \mathrm{l}$, with $2 \mu \mathrm{l}$ used in $\mathrm{qPCR}$ assays for specificity testing (Fig. 2). For testing specificity of other isolates at various starting DNA concentrations (Table 2), mycelia were harvested with sterilized wooden stirrers (STR Supplies Inc.) into sterile $1.5-\mathrm{ml}$ tubes. The tube was plugged with a sterile cotton ball, and mycelia were lyophilized for $48 \mathrm{~h}$. Approximately $20 \mathrm{mg}$ of lyophilized mycelia were ground with three to five 2-mm glass beads and subjected to the same extraction protocol as described above.

qPCR assay sensitivity. Extracted DNA from four $F$. brasiliense isolates was tested for sensitivity via serial dilutions. Concentrations tested were 10-fold dilutions beginning with 1,000,000 fg (1 ng) of F. brasiliense DNA to $10 \mathrm{fg}$ (Fig. 3A). The cycle threshold (Ct) values for each concentration were averaged across isolates, because ribosomal DNA copy number can vary among strains of the same species (Balajee et al. 2009; Wang et al. 2015). The qPCR efficiency was calculated by finding the line of best fit on a plot with the logarithm of the DNA concentrations and their respective $\mathrm{Ct}$ value (Fig. 3B and Table 3). The limit of detection was determined by samples showing $>95 \%$ amplification at the lowest DNA concentration tested (Bustin et al. 2009).

Assay validation. A field site in Ingham County, MI was planted with a randomized complete block design containing two dry bean cultivars (Zenith and Red Hawk) and three treatments (noninoculated, $F$. brasiliense inoculated, and $F$. oxysporum inoculated), with four plot replicates per cultivar $\times$ treatment combination. Each plot was 6.1-m (20-ft) long, with four rows of plants with 76-cm (30-inch) row spacing. The plots were planted on 8 June 2018 at 172,100 seeds $\mathrm{ha}^{-1}$ for Red Hawk and 193,700 seeds ha ${ }^{-1}$ for Zenith using a cone planter. Inoculum was produced on autoclaved sorghum grains as

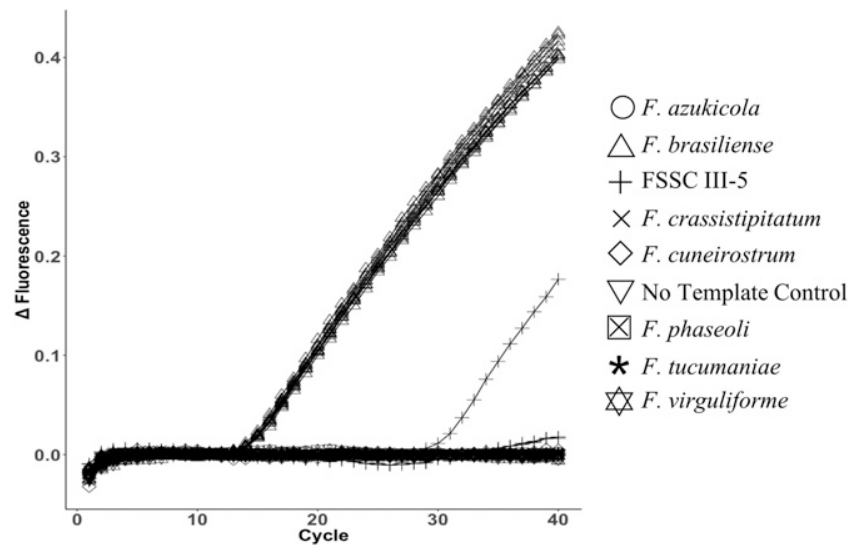

Fig. 2. Amplification results of $5 \mathrm{ng}$ of DNA of select isolates across different species within the Fusarium solani species complex (FSSC). Isolates represented are Fusarium azukicola isolates NRRL 54361 and 54362; Fusarium brasiliense isolates F-14-42, F-15-158, F-16-137, NRRL 34938, and MI-Mtc-C1; Fusarium solan (FSSC 5) isolates MI-Mtc-B10 and F-15-118; Fusarium crassistipitatum isolate NRRL 31949; no template (water) control; Fusarium cuneirostrum F-14-52; Fusarium phaseoli isolates MI-Mtc-A12 and NRRL 22411; Fusarium tucumaniae isolates NRRL 43334 and 31777; and Fusarium virguliforme isolates DB P28 R13 and $\mathrm{Vb}-2 \mathrm{a}$.

Table 2. (Continued from previous page)

\begin{tabular}{|c|c|c|c|c|c|}
\hline Isolate $^{a}$ & Species $^{\mathbf{b}}$ & Host & Location isolated & Assay result ${ }^{c}$ & $\begin{array}{c}\text { Ct with } 5 \mathrm{ng} \\
\text { of starting } \\
\text { DNA }^{\mathrm{d}}\end{array}$ \\
\hline F5 & Fusarium oxysporum & Solanum tuberosum & Michigan, U.S.A. & - & \\
\hline F-16-16 & Fusarium phaseoli & Glycine $\max$ & Montcalm County, MI, U.S.A. & - & \\
\hline MI-Mtc-A12 & Fusarium phaseoli & Glycine $\max$ & Montcalm County, MI, U.S.A. & - & n.d. \\
\hline 22158 & Fusarium phaseoli & Phaseolus vulgaris & Rockville, MD, U.S.A. & - & \\
\hline 22276 & Fusarium phaseoli & Phaseolus vulgaris & Rockville, MD, U.S.A. & - & \\
\hline MI-Mtc-A4 & Fusarium phaseoli & Glycine $\max$ & Montcalm County, MI, U.S.A. & - & \\
\hline 22411 & Fusarium phaseoli & Phaseolus vulgaris & California, U.S.A. & - & n.d. \\
\hline 36549 & Fusarium proliferatum & Gladiolus sp. & The Netherlands & - & \\
\hline MI-Mtc-C3FS (Wht) & FSSC 11 & Glycine max & Montcalm County, MI, U.S.A. & - & \\
\hline MI-Mtc-A2FS & FSSC 11 & Glycine $\max$ & Montcalm County, MI, U.S.A. & + & 21.13 \\
\hline F-15-118 & Fusarium solani (FSSC 5) & Phaseolus vulgaris & Montcalm County, MI, U.S.A. & - & n.d. \\
\hline MI-Mtc-C17FS & Fusarium solani (FSSC 5) & Glycine max & Montcalm County, MI, U.S.A. & - & \\
\hline MI-Mtc-B16FS & Fusarium solani (FSSC 5) & Glycine $\max$ & Montcalm County, MI, U.S.A. & - & \\
\hline MI-Mtc-B10 & Fusarium solani (FSSC 5) & Glycine $\max$ & Montcalm County, MI, U.S.A. & + & 30.43 \\
\hline 31777 & Fusarium tucumaniae & Glycine max & $\begin{array}{l}\text { Vila Maria, Rio Grande } \\
\text { do Sul, Brazil }\end{array}$ & - & n.d. \\
\hline 43334 & Fusarium tucumaniae & Glycine $\max$ & Armstrong, Sante Fe, Argentina & - & n.d. \\
\hline 31096 & Fusarium tucumaniae & Unknown & Argentina & - & \\
\hline DB P28 R13 & Fusarium virguliforme & Phaseolus vulgaris & Van Buren County, MI, U.S.A. & - & n.d. \\
\hline $\mathrm{Vb}-2 \mathrm{a}$ & Fusarium virguliforme & Glycine $\max$ & Van Buren County, MI, U.S.A. & - & n.d. \\
\hline F-14-77 & Fusarium virguliforme & Glycine max & Ingham County, MI, U.S.A. & - & \\
\hline DB P27 R13 & Fusarium virguliforme & Phaseolus vulgaris & Van Buren County, MI, U.S.A. & - & \\
\hline DB P30 R5 & Fusarium virguliforme & Phaseolus vulgaris & Van Buren County, MI, U.S.A. & - & \\
\hline 22292 (Mont-1) & Fusarium virguliforme & Glycine max & Illinois, U.S.A. & - & \\
\hline 36897 & Fusarium virguliforme & Glycine max & Argentina & - & \\
\hline 54291 & Fusarium virguliforme & Glycine $\max$ & Argentina & - & \\
\hline \multirow[t]{7}{*}{ VB-1 } & Fusarium virguliforme & Glycine $\max$ & Van Buren County, MI, U.S.A. & - & \\
\hline & Rhizoctonia solani (AG2-2) & Glycine max & & - & \\
\hline & Rhizoctonia solani (AG4) & Glycine $\max$ & & - & \\
\hline & Phialophora gregata (genotype A) & Glycine $\max$ & & - & \\
\hline & Phialophora gregata (genotype B) & Glycine $\max$ & & - & \\
\hline & Macrophomina phaseolina & Glycine $\max$ & & - & \\
\hline & Sclerotinia sclerotiorum & Glycine $\max$ & & - & \\
\hline
\end{tabular}


described in Wang et al. (2019a). Inoculum was packaged into envelopes directly with seeds, and the contents were poured into the cone planter, sowing the seeds and inoculum in furrow at an average rate of $7.1 \mathrm{ml}$ of inoculum per foot. Three plants from each plot were sampled on 12 September 2018. The foliar tissues were removed from the roots in the field, and the roots were thoroughly washed clean of soil and allowed to dry at $55^{\circ} \mathrm{C}$ for 2 days. The dried roots from each sample were placed in a 50-ml plastic container (OPS Diagnostics) with two 1-cm-diameter steel balls and ground into a powder using a GenoGinder 2010 (SPEX Sample Prep) at 1,500 rpm for $5 \mathrm{~min}$. DNA was extracted from these roots using the same phenol:chloroform procedure described above. Total DNA was quantified using a Nanodrop 1000 (Thermo-Fisher Scientific).

To validate the assay with soil samples, bulk soil was collected from 10 soybean fields throughout Michigan during the spring and summer of 2018 using a 3-cm-diameter, 15-cm-deep soil core. Soil was placed into a 3.8-liter (1-gallon) plastic bag, homogenized, subsampled into $2.3-\mathrm{kg}$ (5-pound) paper bags, and dried at $55^{\circ} \mathrm{C}$ for 2 days. Approximately $500 \mathrm{mg}$ of dried soil was used for DNA extraction using a FastDNA Spin Kit for Soil (MP Bio). Two technical DNA extraction replicates were performed, and a third technical replicate was extracted after being spiked with $\sim 5,000 F$. brasiliense conidia. An estimated number of conidia in nonspiked soil samples that showed positive qPCR results was obtained by performing the following calculation: 5,000 spores $\times z=x$ spores $\times y$, where 5,000 is the number of spores spiked into each soil sample, $z$ is the $\mathrm{Ct}$ of the spiked sample, and $y$ is the $\mathrm{Ct}$ of the nonspiked sample. Nonspiked samples that amplified at a $\mathrm{Ct}>31$ cannot be reliably quantified, because they are below the limit of detection. Therefore, an estimated number of conidia was not calculated for these samples (Table 4).

To test the multiplexing capacity and transferability of this assay on other platforms, serial dilutions of $F$. virguliforme DNA and $F$. brasiliense DNA were amplified in a single reaction containing primers F6-3 and R6 and probe FvPrb-3 (Wang et al. 2015) along with the primers and probe developed in this study (Table 1). Reactions were set up in LightCycler 480 96-well plates (Roche Diagnostics) and performed on a CFX96 Real-Time PCR Detection System v3.1 (BioRad Laboratories). Multiplexed reactions were set up as described above.

\section{Results}

Assay design. A 149-bp segment in the IGS was identified as containing $F$. brasiliense-specific SNPs, and the primers and probe were designed in this region (Fig. 1). The forward primer encompasses one SNP shared by $F$. brasiliense, $F$. cuneirostrum, $F$. crassistipitatum, and $F$. virguliforme but excludes $F$. phaseoli and $F$. tucumaniae. The reverse primer is conserved among all species used in the IGS alignment. The probe encompasses two SNPs unique and specific to $F$. brasiliense, containing two thymines instead of two cytosines. The probe associated with these residues was designed with locked nucleic acid bases to enhance specific binding at these sites (Fig. 1, asterisks). The primers and probe are not

Table 3. Serial dilutions for four Fusarium brasiliense isolates used to determine assay sensitivity

\begin{tabular}{lrrrr}
\hline Isolate $^{\mathbf{a}}$ & $\begin{array}{c}\text { DNA } \\
\text { concentration }^{\mathbf{b}}\end{array}$ & $\mathbf{C t}^{\mathbf{c}}$ & $\begin{array}{c}\text { Mean } \\
\text { Ct }\end{array}$ & $\begin{array}{c}\text { Standard } \\
\text { error }\end{array}$ \\
\hline F-14-42 & $1,000,000$ & 17.20 & 17.22 & 0.099 \\
F-15-158 & $1,000,000$ & 16.82 & & \\
F-16-137 & $1,000,000$ & 17.37 & & \\
NRRL 34938 & $1,000,000$ & 17.50 & & \\
F-14-42 & 100,000 & 20.50 & 20.49 & 0.075 \\
F-15-158 & 100,000 & 20.22 & & \\
F-16-137 & 100,000 & 20.57 & & \\
NRRL 34938 & 100,000 & 20.69 & & \\
F-14-42 & 10,000 & 24.08 & 24.08 & 0.097 \\
F-15-158 & 10,000 & 23.72 & & \\
F-16-137 & 10,000 & 24.33 & & \\
NRRL 34938 & 10,000 & 24.17 & & \\
F-14-42 & 1,000 & 27.65 & 27.66 & 0.079 \\
F-15-158 & 1,000 & 27.35 & & \\
F-16-137 & 1,000 & 27.92 & & \\
NRRL 34938 & 1,000 & 27.72 & & \\
F-14-42 & 100 & 30.96 & 31.18 & 0.139 \\
F-15-158 & 100 & 30.86 & & \\
F-16-137 & 100 & 31.28 & & \\
NRRL 34938 & 100 & 31.62 & & \\
F-14-42 & 10 & 35.26 & 34.93 & 0.249 \\
F-15-158 & 10 & 33.93 & & \\
F-16-137 & 10 & 35.36 & & \\
NRRL 34938 & 10 & 35.16 & & \\
\hline
\end{tabular}

${ }^{a}$ Isolate 34938 was obtained from the U.S. Department of Agriculture Agricultural Research Service (ARS) Culture Collection (NRRL). All other isolates were obtained by J. L. Jacobs and M. I. Chilvers.

b Concentration in femtograms of DNA per reaction.

${ }^{\mathrm{c}} \mathrm{Ct}$, cycle threshold (or cycle at which fluorescent signal crossed the detection threshold).
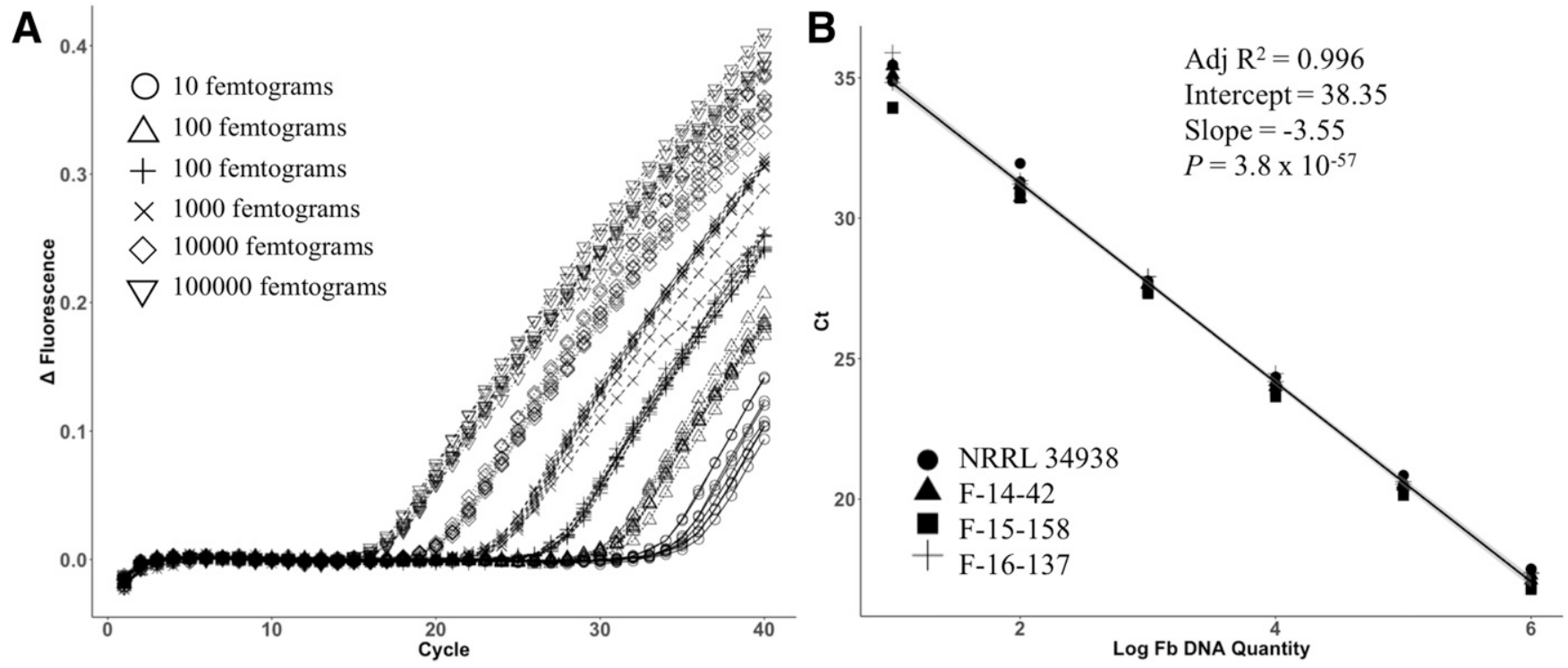

Fig. 3. A, Detection of serial dilutions of four Fusarium brasiliense (Fb) isolates to determine assay sensitivity. B, These isolates consistently amplified at all concentrations tested, with an average of $99.6 \%$ efficiency. 
predicted to form any significant homo- or heterodimers $(\Delta \mathrm{G}>$ -9) and perform at an ideal anneal and extension temperature of $60^{\circ} \mathrm{C}$.

qPCR assay specificity. Genomic DNA isolated from purified mycelia was used to show specificity across closely related species within clade 2 of the FSSC (Table 2). The only isolates displaying amplification were $F$. brasiliense and some members of FSSC clade 3 (Chitrampalam and Nelson 2016) (Fig. 2 and Table 2). However, when tested with a standard $5 \mathrm{ng}$ of starting DNA, F. brasiliense isolates consistently had $\mathrm{Ct}$ values within $1 \mathrm{Ct}$ of each other (13.94 to 14.92) (Table 2). In contrast, FSSC clade 3 isolates with positive reactions had higher $\mathrm{Ct}$ values. These results indicate that the assay designed here can distinguish $F$. brasiliense from closely related clade 2 species and other common soilborne pathogenic fungi (Table 2). However, there may be some cross-reactivity with clade 3 species. With pure cultures, $F$. brasiliense can readily be distinguished from clade 3 species based on growth rate and morphology (Fig. 4).

Table 4. Amplification of Fusarium brasiliense from soils across Michigan

\begin{tabular}{llccc}
\hline Location in Michigan & Type & $\mathbf{C t}^{\mathbf{a}}$ & Quantity DNA detected $^{\mathbf{b}}$ & Spores per 500 mg of soil $^{\mathbf{c}}$ \\
\hline Clinton County & Unknown & - & - & - \\
Clinton County & Spiked & 21.26 & 57,083 & 5,000 \\
Hillsdale County & Unknown & - & - & - \\
Hillsdale County & Spiked & 18.10 & 346,132 & 5,000 \\
Lenawee County & Unknown & 36.92 & 108,360 & n.d. \\
Lenawee County & Spiked & 20.14 & 137 & 5,000 \\
Montcalm County & Unknown & 32.03 & 226,150 & n.d. \\
Montcalm County & Spiked & 18.90 & 39 & 5,000 \\
Ingham County & Unknown & 34.13 & 547,582 & n.d. \\
Ingham County & Spiked & 17.29 & 246 & 5,000 \\
Saginaw County & Unknown & 30.83 & 363,252 & 2,804 \\
Saginaw County & Spiked & 18.01 & 529 & 5,000 \\
Sanilac County & Unknown & 29.51 & 512,226 & 74 \\
Sanilac County & Spiked & 17.41 & 137,118 & 5,052 \\
St. Joseph County & Unknown & 32.95 & - & n.d. \\
St. Joseph County & Spiked & 19.72 & 123,579 & - \\
Van Buren County, Field 1 & Unknown & - & - & 5,000 \\
Van Buren County, Field 1 & Spiked & 19.90 & 70,167 & - \\
Van Buren County, Field 2 & Unknown & - & 5,000 \\
Van Buren County, Field 2 & Spiked & 21.97 & 5,000 \\
\hline
\end{tabular}

${ }^{a} \mathrm{Ct}$, cycle threshold (or cycle at which fluorescent signal crossed the detection threshold).

${ }^{\mathrm{b}}$ Quantity in femtograms.

${ }^{c}$ Estimated by solving for $x$ using the equation 5,000 spores $\times z=x$ spores $\times y$, where 5,000 is the number of spores spiked into each soil sample, $z$ is the Ct of the spiked sample, and $y$ is the $\mathrm{Ct}$ of the nonspiked sample. Dashes indicate no detection, and n.d. indicates not determined, because detection was below the limit of detection.

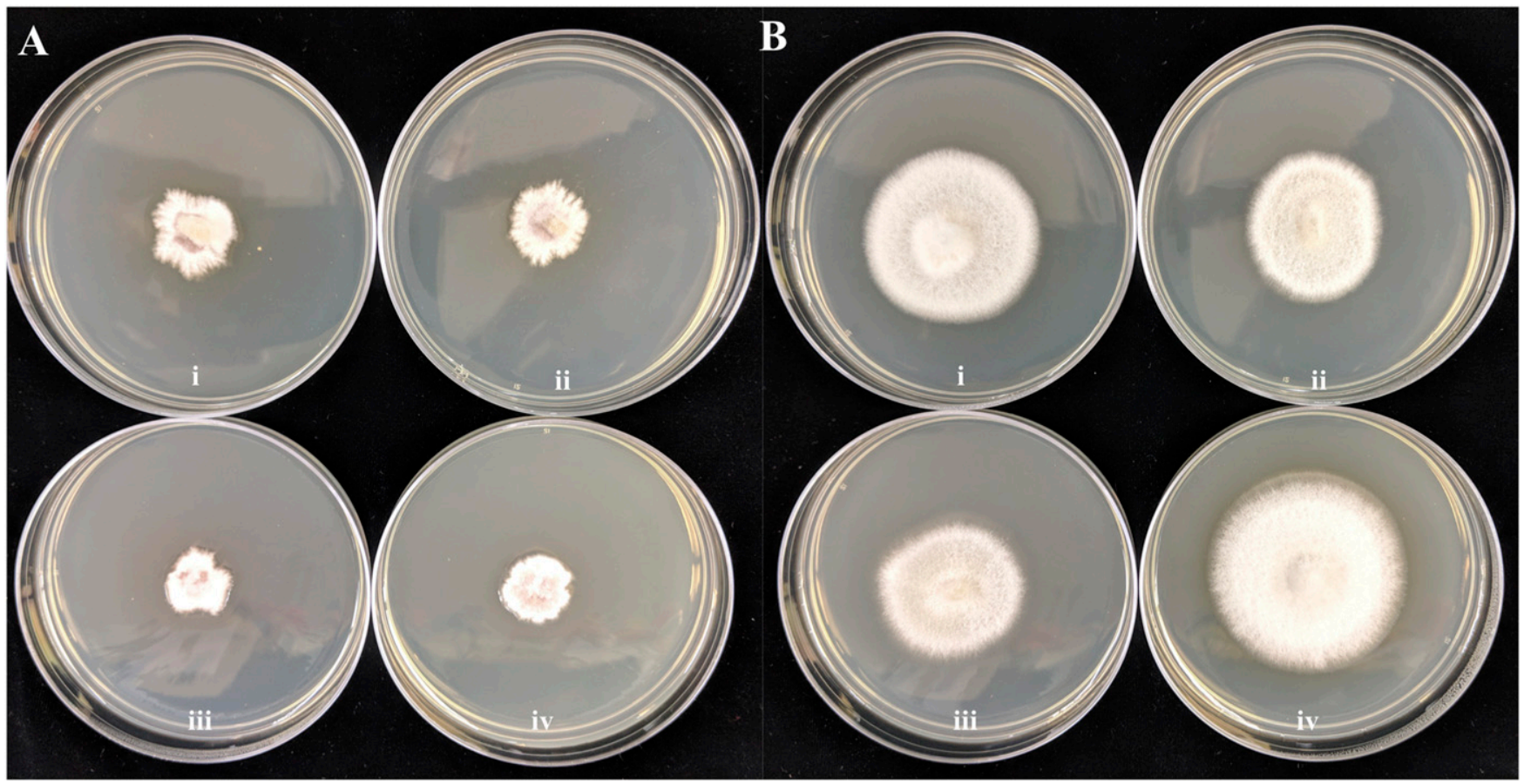

Fig. 4. Representative isolates of A, Fusarium brasiliense and B, Fusarium solani species complex (FSSC) clade 3 isolates plated on potato dextrose agar 7 days post inoculation A, F. brasiliense isolates represented are i, MI-Mtc-C1; ii, MI-Mtc-A13; iii, F-16-137; and iv, F-15-158. B, F. solani (FSSC 5) isolates represented are i, MI-Mtc-C17FS; ii, MI-MtcB16FS; and iii, MI-Mtc-B10, whereas iv, FSSC 11 isolate MI-Mtc-A2FS is also represented. 
qPCR assay sensitivity. The $F$. brasiliense qPCR assay targeting the IGS region provided high sensitivity, reproducibly amplifying target DNA as low as $10 \mathrm{fg}$ of target DNA of multiple isolates (Fig. 3). Although all four isolates tested here amplified at this low concentration, standard error of detection was highest at this concentration. Therefore, the limit of detection was conservatively determined to be $100 \mathrm{fg}$ or a $\mathrm{Ct} \geq 31$ (Table 3) (Bustin et al. 2009). Although target DNA can be amplified at lower concentrations, quantities determined below this $\mathrm{Ct}$ may not be reliable.

Assay validation. To determine the applicability of this assay to field trials, roots from artificially inoculated dry beans were harvested, subjected to DNA extraction, and tested with the $F$. brasiliense qPCR assay developed here. F. brasiliense was detected consistently above the limit of detection in dry bean plots inoculated with $F$. brasiliense (average $\mathrm{Ct}=29.6$ ) but not in noninoculated plots or plots inoculated with $F$. oxysporum (average $\mathrm{Ct}=36.3$ ) (Fig. 5).

Soil samples obtained from 10 counties throughout Michigan were screened for the presence of $F$. brasiliense. All soil samples spiked with $F$. brasiliense conidia were successfully detected with $C t$ values ranging from 17.29 to 21.97 , indicating relatively pure DNA samples lacking PCR inhibitors (Table 4). Additionally, F. brasiliense was detected in nonspiked soil samples from six counties, although only two were confidently above the limit of detection of $100 \mathrm{fg}$ (Table 4). Using a known quantity of spores in the spiked samples, estimated 2,804 and 3,051 spores were present in Saginaw County and Sanilac County, respectively, per $500 \mathrm{mg}$ of soil.

The primers and probes for the F. brasiliense assay and a $F$. virguliforme assay (Wang et al. 2015) were used simultaneously in a multiplexed reaction (Table 1). Amplification for each assay was only observed when target DNA was present, indicating no crossreactivity between the assays (Table 5). Combinations of serial dilutions of $F$. brasiliense and $F$. virguliforme DNA were successfully amplified in pooled reactions, and an accurate quantification of each target was obtained (Table 5).

\section{Discussion}

Many of the clade 2 species in the FSSC are economically important pathogens capable of causing root rot and/or soybean SDS and significant yield losses. They are very similar morphologically, with a slow growth rate, and they are taxonomically distinguished by conidia measurements and number of septa (Aoki et al. 2014). However, because a pure culture is required to obtain conidia and because conidia measurements of these species overlap (Aoki et al. 2003), it can
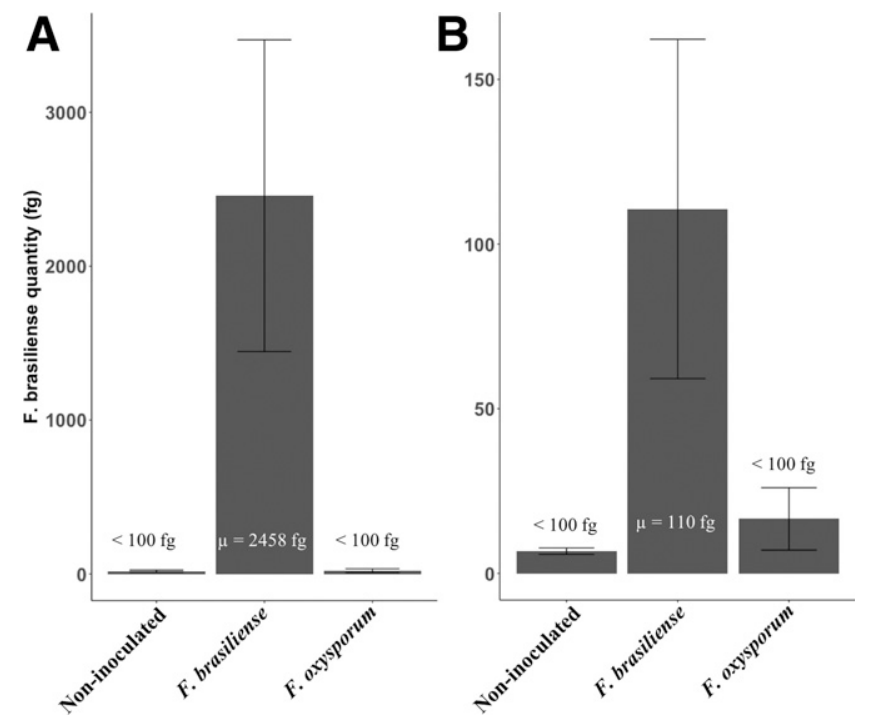

Fig. 5. Detection of Fusarium brasiliense within root tissues of dry bean A, cultivar Zenith or B, cultivar Red Hawk. Values listed over bars indicate the average femtograms of $F$. brasiliense DNA detected within roots of 12 plants per treatment. Noninoculated and Fusarium oxysporum-inoculated samples were not detected above the limit of detection of $100 \mathrm{fg}$. be very difficult to obtain accurate identifications in a timely manner, if at all, using morphology alone. DNA extractions and qPCR assays can be performed in a single day, expediting accurate diagnoses. High-quality qPCR assays have high sensitivity and are capable of detecting very low quantities of target DNA. Designing an assay around a multicopy target, like the IGS region, can increase sensitivity. Previous assays designed around the IGS region have provided sensitivity to as low as $100 \mathrm{fg}$ of target DNA (Rojas et al. 2017; Wang et al. 2015). The assay developed here has validated SNPs specific to $F$. brasiliense compared with other species within the FSSC clade 2 (Fig. 1 and Table 2). The assay performs at a high efficiency of $99.6 \%$, and it consistently detected $10 \mathrm{fg}$ of target DNA when obtained from pure culture and has a confident limit of detection of $100 \mathrm{fg}$ (Fig. 3 and Table 3).

Nomenclature within clade 3 of the FSSC is complicated, but progress has been made by incorporating multilocus genotyping and formal typification efforts (Coleman 2016; O'Donnell et al. 2010; Schroers et al. 2016). For instance, FSSC clade 3 species in this study represent FSSC 5, the true $F$. solani, and FSSC 11, an unnamed species. Interestingly, F. solani (FSSC 5) and FSSC 11 qPCR results showed variation among isolates, suggesting some IGS sequence diversity within these species. Sanger sequencing of the 149-bp IGS region where this qPCR assay was designed showed that FSSC 11 isolate MI-Mtc-C3FS (Wht) and F. solani isolates F-15-118 and MI-Mtc-C17FS share SNPs with other non- $F$. brasiliense species, confirming their negative reactions. Sanger sequencing of this region for FSSC 11 isolate MI-Mtc-A2FS and F. solani isolate MI-Mtc-B10 showed SNPs shared with $F$. brasiliense, thus explaining the positive reactions. Phylogenetic analyses of $F$. solani clade 3 isolates commonly use other molecular markers, such as TEF1, internal transcribed spacer (ITS) ribosomal DNA, and $R P B 2$ (Chitrampalam and Nelson 2016; Wang et al. 2019b), perhaps because of the difficulty of sequencing and assembling the repetitive IGS region. However, this assay provides specificity to $F$. brasiliense within $F$. solani clade 2, and qPCR-positive FSSC clade 3 strains can be distinguished from $F$. brasiliense through morphology (Fig. 4). However, the identity of all isolates should be confirmed through PCR and Sanger sequencing of multiple loci (Wang et al. 2019b).

When pure cultures and collections are not being obtained or maintained, this assay can still provide an initial screen for $F$. brasiliense in soil and root samples. The assay is not likely to produce false-positive results by cross-amplification of FSSC clade 3 species, because some

Table 5. Amplification of serial dilutions of Fusarium brasiliense and/or Fusarium virguliforme DNA in a multiplexed system ${ }^{\mathrm{a}}$

\begin{tabular}{lrcc}
\hline $\begin{array}{l}\boldsymbol{F} \text {. virguliforme } \\
\text { DNA added }\end{array}$ & $\begin{array}{l}\text { F. brasiliense } \\
\text { DNA added }^{\mathbf{b}}\end{array}$ & $\boldsymbol{F}_{\text {. virguliforme }} \mathbf{C t}^{\mathbf{c}}$ & $\boldsymbol{F}_{\text {. brasiliense } \mathbf{C t}^{\mathbf{d}}}$ \\
\hline $1,000,000$ & 0 & 17.35 & - \\
100,000 & 0 & 20.95 & - \\
10,000 & 0 & 24.46 & - \\
1,000 & 0 & 28.10 & - \\
100 & 0 & 31.53 & - \\
0 & $1,000,000$ & - & 17.57 \\
0 & 100,000 & - & 21.02 \\
0 & 10,000 & - & 24.17 \\
0 & 1,000 & - & 26.60 \\
0 & 100 & - & 31.80 \\
$1,000,000$ & $1,000,000$ & 17.49 & 18.86 \\
10,000 & $1,000,000$ & 24.74 & 17.26 \\
10,000 & 100,000 & 24.52 & 20.73 \\
100 & 100,000 & 33.34 & 20.87 \\
1,000 & 10,000 & 28.02 & 23.61 \\
100 & 1,000 & 31.82 & 27.00 \\
0 & 0 & - & - \\
\hline
\end{tabular}

a Dashes represent no detection.

${ }^{\mathrm{b}}$ Quantity in femtograms.

${ }^{c} \mathrm{Ct}$, cycle threshold (cycle at which fluorescent signal crossed the detection threshold for $F$. virguliforme).

${ }^{\mathrm{d}} \mathrm{Ct}$, cycle threshold (cycle at which fluorescent signal crossed the detection threshold for $F$. brasiliense). 
do not cross-react even at high concentrations, and others that do crossreact do so with much lower efficiency, producing significantly higher $\mathrm{Ct}$ values (Fig. 2 and Table 2). For instance, with $5 \mathrm{ng}$ of purified fungal DNA, cross-reactive FSSC clade 3 species showed higher $\mathrm{Ct}$ values by at least six cycles (Table 2). Therefore, obtaining a sufficient concentration of FSSC clade 3 DNA from root or soil samples for cross-reactivity is unlikely. In contrast, all $F$. brasiliense isolates from both the United States and Brazil were consistently detected with high accuracy and efficiency. Therefore, obtaining a sufficient concentration of $F$. brasiliense from root or soil samples for successful amplification and detection is possible as shown in Figure 5 and Table 4. Initial screens with this qPCR assay can help guide when and where to begin isolation attempts for pure cultures, and they can also help generate an understanding of the global distribution of $F$. brasiliense. For example, the $F$. brasiliense assay gave $\mathrm{Ct}$ values $<31$ from soil samples from Saginaw and Sanilac Counties, where $F$. brasiliense has already been successfully isolated from plant roots (K. A. Oudman et al., unpublished data). The assay also gave $\mathrm{Ct}$ values $>31$ but $<36$ with DNA from soil samples from Montcalm and Ingham Counties, where $F$. brasiliense has also been successfully isolated (K. A. Oudman et al., unpublished data). Finally, the assay gave $\mathrm{Ct}$ values $>31$ but $<36$ from Lenawee and St. Joseph soils, where $F$. brasiliense has not yet been isolated. Therefore, the assay provides evidence that warrants additional investigation and isolation attempts for $F$. brasiliense from these counties.

Soybean and dry bean are valuable crops in Michigan worth a combined \$1.08 billion in 2017 (USDA-NASS 2017). Fusarium root rot and SDS consistently rank in the top 10 most destructive soybean diseases in northern states, including Michigan (Allen et al. 2017). Genetic resistance to Fusarium root rot is partial, and only a few fungicides are effective against it (Sang et al. 2018; Wang et al. 2017). Therefore, accurate detection and integrating successful management practices, like using seed treatments (Kandel et al. 2018), crop rotations (Leandro et al. 2018), tillage practices, and planting partially resistant cultivars, are key to preventing yield loss. Additional understanding of a possible host preference is also needed to inform management strategies, because $F$. brasiliense is more commonly found in areas of dry bean production, whereas $F$. virguliforme is more commonly found in areas of soybean production in Michigan (K. A. Oudman et al., unpublished data). Preliminary experiments examining host preference have shown that both $F$. brasiliense and $F$. virguliforme cause disease on both soybean and dry bean and that disease severity and root colonization are not significantly different from one another in a growth chamber setting (M. G. Roth and M. I. Chilvers, unpublished data). Symptomatic roots infected by $F$. brasiliense and $F$. virguliforme are indistinguishable from one another, and coinfections may also be possible. Therefore, the ability to multiplex the $F$. brasiliense and $F$. virguliforme assays can also save time and effort in accurate diagnoses.

Partial genetic resistance will continue to be an important part of integrated management for Fusarium root rot pathogens. Although more research has been done with resistance to Fusarium spp. in soybean, resistance is complicated and partial (Chang et al. 2018). Dry beans (P. vulgaris) originated from Mesoamerica (Bitocchi et al. 2012), but they were traded through Central America and experienced a genetic bottleneck while reaching South America. Therefore, gene pools in current bean breeding lines originate from Mesoamerica or the northern Andean region of South America (Bellucci et al. 2014; Miklas et al. 2006; Singh 2001; Singh and Schwartz 2010). Dry bean varieties from Mesoamerican gene pools, like Zenith, are smaller in size and typically have higher resistance to root rot diseases (Román-Avilés and Kelly 2005; Schneider et al. 2001). Another Mesoamerican variety, Zorro, was shown to have more resistance to $F$. virguliforme than the Andean variety Red Hawk, a large-seeded red kidney bean cultivar (Michigan Dry Edible Bean Production Research Advisory Board 2017). Interestingly, more $F$. brasiliense was detected in inoculated Zenith roots than Red Hawk roots in this study. However, root colonization and disease severity are not always strongly correlated, particularly among the clade 2 FSSC species (Wang et al. 2019a). A formal study should be conducted to determine the inherent resistance levels of multiple varieties from the two different gene pools to $F$. brasiliense.

\section{Acknowledgments}

The authors thank Z. A. Noel, M. Breunig, V. Ortiz, and A. G. McCoy for helpful discussions and manuscript revisions.

\section{Literature Cited}

Allen, T. W., Bradley, C. A., Sisson, A. J., Byamukama, E., Chilvers, M. I., Coker, C. M., Collins, A. A., Damicone, J. P., Dorrance, A. E., Dufault, N. S., Esker, P. D., Faske, T. R., Giesler, L. J., Grybauskas, A. P., Hershman, D. E., Hollier, C. A., Isakeit, T., Jardine, D. J., Kelly, H. M., Kemerait, R. C., Kleczewski, N. M., Koenning, S. R., Kurle, J. E., Malvick, D. K., Markell, S. G., Mehl, H. L., Mueller, D. S., Mueller, J. D., Mulrooney, R. P., Nelson, B. D., Newman, M. A., Osborne, L., Overstreet, C., Padgett, G. B., Phipps, P. M., Price, P. P., Sikora, E. J., Smith, D. L., Spurlock, T. N., Tande, C. A., Tenuta, A. U., Wise, K. A., and Wrather, J. A. 2017. Soybean yield loss estimates due to diseases in the United States and Ontario, Canada, from 2010 to 2014. Plant Health Prog. 18:19-27.

Aoki, T., O'Donnell, K., and Geiser, D. M. 2014. Systematics of key phytopathogenic Fusarium species: current status and future challenges. J. Gen. Plant Pathol. 80:189-201.

Aoki, T., O’Donnell, K., Homma, Y., and Lattanzi, A. R. 2003. Suddendeath syndrome of soybean is caused by two morphologically and phylogenetically distinct species within the Fusarium solani species complex - F. virguliforme in North America and F. tucumaniae in South America. Mycologia 95:660-684.

Aoki, T., O'Donnell, K., and Scandiani, M. M. 2005. Sudden death syndrome of soybean in South America is caused by four species of Fusarium: Fusarium brasiliense sp. nov., $F$ cuneirosrum sp. nov., $F$. tucumaniae, and $F$. virguliforme. Mycoscience 46:162-183.

Aoki, T., Scandiani, M. M., and O'Donnell, K. 2012a. Phenotypic, molecular phylogenetic, and pathogenetic characterization of Fusarium crassistipitatum sp. nov., a novel soybean sudden death syndrome pathogen from Argentina and Brazil. Mycoscience 53:167-186.

Aoki, T., Tanaka, F., Suga, H., Hyakumachi, M., Scandiani, M. M., and O'Donnell, K. 2012b. Fusarium azukicola sp. nov., an exotic azuki bean root-rot pathogen in Hokkaido, Japan. Mycologia 104:1068-1084.

Balajee, S. A., Borman, A. M., Brandt, M. E., Cano, J., Cuenca-Estrella, M., Dannaoui, E., Guarro, J., Haase, G., Kibbler, C. C., Meyer, W., O'Donnell, K., Petti, C. A., Rodriguez-Tudela, J. L., Sutton, D., Velegraki, A., and Wickes, B. L. 2009. Sequence-based identification of Aspergillus, Fusarium, and Mucorales species in the clinical mycology laboratory: where are we and where should we go from here? J. Clin. Microbiol. 47:877-884.

Bellucci, E., Bitocchi, E., Rau, D., Rodriguez, M., Biagetti, E., Giardini, A., Attene, G., Nanni, L., and Papa, R. 2014. Genomics of origin, domestication and evolution of Phaseolus vulgaris. Pages 483-507 in: Genomics of Plant Genetic Resources. R. Tuberosa, A. Graner, and E. Frison, eds. Springer, Dordrecht, The Netherlands.

Bitocchi, E., Nanni, L., Bellucci, E., Rossi, M., Giardini, A., Zeuli, P. S., Logozzo, G., Stougaard, J., McClean, P., Attene, G., and Papa, R. 2012. Mesoamerican origin of the common bean (Phaseolus vulgaris L.) is revealed by sequence data. Proc. Natl. Acad. Sci. 109:E788-E796.

Bustin, S. A., Benes, V., Garson, J. A., Hellemans, J., Huggett, J., Kubista, M., Mueller, R., Nolan, T., Pfaffl, M. W., Shipley, G. L., Vandesompele, J., and Wittwer, C. T. 2009. The MIQE guidelines: minimum information for publication of quantitative real-time PCR experiments. Clin. Chem. 55: 611-622.

Chang, H. X., Roth, M. G., Wang, D., Cianzio, S. R., Lightfoot, D. A., Hartman, G. L., and Chilvers, M. I. 2018. Integration of sudden death syndrome resistance loci in the soybean genome. Theor. Appl. Genet. 131:757-773.

Chilvers, M. I., du Toit, L. J., Akamatsu, H., and Peever, T. L. 2007. A real-time, quantitative PCR seed assay for Botrytis spp. that cause neck rot of onion. Plant Dis. 91:599-608.

Chitrampalam, P., and Nelson, B. 2016. Multilocus phylogeny reveals an association of agriculturally important Fusarium solani species complex (FSSC) 11, and clinically important FSSC 5 and FSSC $3+4$ with soybean roots in the north central United States. Antonie van Leeuwenhoek, Int. J. Genet. Mol. Microbiol. 109:335-347.

Coleman, J. J. 2016. The Fusarium solani species complex: ubiquitous pathogens of agricultural importance. Mol. Plant Pathol. 17:146-158.

Edgar, R. C. 2004. MUSCLE: multiple sequence alignment with high accuracy and high throughput. Nucleic Acids Res. 32:1792-1797.

Hughes, T. J., O’Donnell, K., Sink, S., Rooney, A. P., Scandiani, M. M., Luque, A., Bhattacharyya, M. K., and Huang, X. 2014. Genetic architecture and evolution of the mating type locus in fusaria that cause soybean sudden death syndrome and bean root rot. Mycologia 106:686-697.

Kandel, Y. R., Mueller, D. S., Legleiter, T., Johnson, W. G., Young, B. G., and Wise, K. A. 2018. Impact of fluopyram fungicide and preemergence herbicides on soybean injury, population, sudden death syndrome, and yield. Crop Prot. 106:103-109. 
Kumar, S., Stecher, G., and Tamura, K. 2016. MEGA7: molecular evolutionary genetics analysis version 7.0 for bigger datasets. Mol. Biol. Evol. 33:1870-1874.

Leandro, L. F. S., Eggenberger, S., Chen, C., Williams, J., Beattie, G. A., and Liebman, M. 2018. Cropping system diversification reduces severity and incidence of soybean sudden death syndrome caused by Fusarium virguliforme. Plant Dis. 102:1748-1758.

Michigan Dry Edible Bean Production Research Advisory Board. 2017. Dry Bean Research Report. https://www.canr.msu.edu/saginawvalley/uploads/files/2017\% 20Dry\%20Bean\%20Report\%20printer\%20pdf\%20(003).pdf

Miklas, P., Kelly, J., Beebe, S., and Blair, M. 2006. Common bean breeding for resistance against biotic and abiotic stresses: from classical to MAS breeding. Euphytica 147:105-131.

O'Donnell, K. 2000. Molecular phylogeny of the Nectria haematococca-Fusarium solani species complex. Mycologia 92:919-938.

O’Donnell, K., Sink, S., Scandiani, M. M., Luque, A., Colletto, A., Biasoli, M., Lenzi, L., Salas, G., González, V., Ploper, L. D., Formento, N., Pioli, R. N., Takayuki, A., Yang, X. B., and Sarver, B. A. J. 2010. Soybean sudden death syndrome species diversity within North and South America revealed by multilocus genotyping. Phytopathology 100:58-71.

Okubara, P. A., Harrison, L. A., Gatch, E. W., Vandemark, G., Schroeder, K. L., and du Toit, L. J. 2013. Development and evaluation of a TaqMan real-time PCR assay for Fusarium oxysporum f. sp. spinaciae. Plant Dis. 97:927-937.

Rojas, J. A., Miles, T. D., Coffey, M. D., Martin, F. N., and Chilvers, M. I. 2017. Development and application of qPCR and RPA genus- and species-specific detection of Phytophthora sojae and P. sansomeana root rot pathogens of soybean. Plant Dis. 101:1171-1181.

Román-Avilés, B., and Kelly, J. D. 2005. Identification of quantitative trait loci conditioning resistance to Fusarium root rot in common bean. Crop Sci. 45: 1881-1890.

Sang, H., Witte, A., Jacobs, J. L., Chang, H.-X., Wang, J., Roth, M. G., and Chilvers, M. I. 2018. Fluopyram sensitivity and functional characterization of $\mathrm{SdhB}$ in the Fusarium solani species complex causing soybean sudden death syndrome. Front. Microbiol. 9:2335.

Schneider, K. A., Grafton, K. F., and Kelly, J. D. 2001. QTL analysis of resistance to Fusarium root rot in bean. Crop Sci. 41:535-542.
Schroers, H.-J., Samuels, G. J., Zhang, N., Short, D. P. G., Juba, J., and Geiser, D. M. 2016. Epitypification of Fusisporium (Fusarium) solani and its assignment to a common phylogenetic species in the Fusarium solani species complex. Mycologia 108:806-819.

Singh, S. P. 2001. Broadening the genetic base of common bean cultivars: a review. Crop Sci. 41:1659-1675.

Singh, S. P., and Schwartz, H. F. 2010. Breeding common bean for resistance to diseases: a review. Crop Sci. 50:2199-2223.

Tewoldemedhin, Y. T., Lamprecht, S. C., Vaughan, M. M., Doehring, G., and O'Donnell, K. 2017. Soybean SDS in South Africa is caused by Fusarium brasiliense and a novel undescribed Fusarium sp. Plant Dis. 101:150-157.

USDA. 2018. World Agricultural Supply and Demand Estimates. https:// downloads.usda.library.cornell.edu/usda-esmis/files/3t945q76s/4q77fw19m/ kk91fq550/latest.pdf

USDA-NASS. 2017. State Agriculture Overview. https://www.nass.usda.gov/ Quick_Stats/Ag_Overview/stateOverview.php?state=MICHIGAN

Wang, H., Xiao, M., Kong, F., Chen, S., Dou, H. T., Sorrell, T., Li, R. Y., and Xu, Y. C. 2011. Accurate and practical identification of 20 Fusarium species by seven-locus sequence analysis and reverse line blot hybridization, and an in vitro antifungal susceptibility study. J. Clin. Microbiol. 49:1890-1898.

Wang, J. 2016. Molecular Diagnostics, Epidemiology, and Population Genetics of the Soybean Sudden Death Syndrome Pathogen, Fusarium virguliforme. https://d.lib.msu.edu/etd/4335

Wang, J., Bradley, C. A., Stenzel, O., Pedersen, D. K., Reuter-Carlson, U., and Chilvers, M. I. 2017. Baseline sensitivity of Fusarium virguliforme to fluopyram fungicide. Plant Dis. 101:576-582.

Wang, J., Jacobs, J. L., Byrne, J. M., and Chilvers, M. I. 2015. Improved diagnoses and quantification of Fusarium virguliforme, causal agent of soybean sudden death syndrome. Phytopathology 105:378-387.

Wang, J., Jacobs, J. L., Roth, M. G., Chilvers, M. I., Sciences, M., and State, M. 2019a. Temporal dynamics of Fusarium virguliforme colonization of soybean roots. Plant Dis. 103:19-27.

Wang, J., Sang, H., Jacobs, J. L., Oudman, K. A., Hanson, L. E., and Chilvers, M. I 2019 b. Soybean sudden death syndrome causal agent Fusarium brasiliense present in Michigan. Plant Dis. 103:1234-1243. 